\title{
A cidade em pauta: imprensa e modernidade carioca nos anos de 1950
}

\author{
The city in the agend: Rio press and modernity in the 1950s
}

\section{Cláudia Mesquita}

Doutora em História Social pela Universidade Federal do Rio de Janeiro Professora da Pós-graduação em História da Universidade Salgado de Oliveira claudiamesquitta@gmail.com

\begin{abstract}
Resumo: A modernidade dos anos de 1950 produziu um novo tipo de sociabilidade, associada ao aceleramento da urbanização e dos meios de comunicação de massa, ao crescimento econômico e a diferenciação de padrões de comportamento. Fenômenos que produziram uma diferenciação maior dos tipos urbanos, estimulada ainda pelo intenso fluxo migratório de outros estados para a capital federal, e pelo estabelecimento de novas territorialidades culturais na cidade do Rio de Janeiro. Esse artigo tem por objetivo refletir sobre esses processos e a importância da imprensa e dos seus repórteres, na construção dessa modernidade carioca na primeira metade do século XX.
\end{abstract}

Palavras-chave: Modernidade, Carioca, Imprensa.

\begin{abstract}
The modernity of the 1950s produced a new type of sociability, associated with the acceleration of urbanization and the mass media, economic growth and the differentiation of behavior patterns. Phenomena that produced a greater differentiation of urban types, further stimulated by the intense migratory flow from other states to the federal capital, and by the establishment of new cultural territorialities in the city of Rio de Janeiro. This article aims to reflect on these processes and the importance of the press and its reporters in the construction of this mid-20th century carioca modernity.
\end{abstract}

Keywords: Modernity, Carioca, Press. 


\section{Introdução}

Esse artigo tem por objetivo abordar a renovação do jornalismo brasileiro em princípios do século XX e nos anos de 1950, associados a padrões diferentes de modernidade, bem como a ascensão e expansão da carreira de repórter nesses contextos. Pretendemos identificar o lugar ocupado pelos repórteres no chamado "mundo dos jornalistas", definido por Isabel Travancas, como "um ethos particular, detentor de uma visão de mundo e estilo de vida característicos" (TRAVANCAS, 1993: 13). Proposição válida, sobretudo, para os românticos jornalistas dos anos de 1950, cujo jornalismo era mesmo uma "cachaça", ou uma "razão de viver", ocupando a maior parte de suas vidas, inclusive pela exigência do tempo integral de "antenamento" com as notícias e, principalmente, pela existência boêmia, que "para os jornalistas daquela época, era quase condição essencial da profissão" (WAINER, 1987).

Esse circuito boêmio funcionava como uma redação informal que se cruzava com o mundo das artes, da literatura, do high society e com a cultura popular. Mediação responsável por promover uma mudança de comportamento, e visões de mundo que se espalhavam pela cidade, criando um estilo de vida associado a um jeito carioca de ser. Por essa razão, o exercício da atividade jornalística não deve estar limitado apenas ao enquadramento formal da profissão, mas a construção de uma comunidade interpretativa, pois agindo enquanto comunidade, os jornalistas foram pródigos na conjugação entre literatura e jornal, ajudando a criar através da mídia escrita um novo perfil de cidade.

Segundo Pierre Bourdieu, as relações de comunicação, onde se inserem as trocas linguísticas são, por excelência, relações de poder simbólico onde se atualizam as relações de força entre locutores e os grupos específicos que detém a fala e, nesse sentido, a imprensa adquire um poder de enunciação e um caráter performativo (BOURDIEU, 1989). Nessa perspectiva, o jornalista pode ser tomado como um intelectual produtor de bens simbólicos, e um "inventor das tradições", para usar a noção proposta por Eric Hobsbawm e Terence Ranger, no sentido em que seria responsável por um conjunto de práticas de natureza ritual ou simbólica, que visa garantir um sentido de unidade, pertencimento, identidade, através da continuidade em relação a um passado histórico apropriado (HOBSBAWM; RANGER, 1997: 9). 
O papel desempenhado pela imprensa no contexto da modernidade, em que observa uma composição cultural a partir de diálogos e confrontos entre as elites e camadas populares, também destaca a importância dos jornalistas como mediadores culturais, no sentido proposto por Gilberto Velho e Karina Kuschnir em suas reflexões sobre o papel dos "viajantes urbanos" nas chamadas sociedades complexas. Para esses autores, a metáfora da viagem não significa "necessariamente um deslocamento geográfico, físico-espacial, mas sobretudo, um trânsito entre subculturas, mundos sociais, tipos de ethos ou, mesmo, papéis sociais de um mesmo indivíduo" (VELHO; KUSCHNIR, 2000: 20).

Segundo Hermano Vianna, a constituição de uma cultura urbana, se deu justamente a partir desse movimento de circularidade cultural iniciado nas primeiras décadas do século XX, a partir da interação entre manifestações de grupos socialmente excluídos e representantes das elites, dando origem a um campo cultural comum (VIANNA, 1995). Desse modo, a figura do repórter nasce associada às ruas do Rio, como locais de encontro e de intercâmbio entre diferentes grupos e matizes culturais, responsável pela aproximação entre as cidades europeia e africana, e pela singularidade de um campo cultural daí decorrente (VELLOSO, 1996).

O "ser moderno" admite muitos sentidos, que "se expressariam por numerosas, mas não arbitrárias, estéticas modernistas" (GOMES, 1999: 12), entre as quais a estética belle époque de princípios do século XX. O centro do Rio tornou-se o epicentro dessa concepção de cidade que buscava distinguir-se do seu perfil de antigo centro colonial, adotando o modelo francês de civilização, presente na arquitetura, culinária, moda e na estética boêmia. O Rio capital federal, cidade paradigmática da modernidade urbana, tinha como missão construir um padrão de referência à identidade nacional, compromisso assumido por algumas de suas principais expressões culturais (VELLOSO, 1996), onde destacamos o papel da imprensa, como determinante nesse processo.

O repórter foi a novidade desses tempos modernos na imprensa carioca, caracterizados pela celeridade das máquinas, como também das notícias. Junto aos cronistas, o repórter foi responsável pela popularização dos jornais, transformando em textos temas do cotidiano, e trazendo para os periódicos coberturas nas áreas de esporte, teatro, carnaval, eventos populares e os casos policiais, até então inexplorados. Por outro lado, como destaca Marialva Barbosa, o nascimento do repórter está diretamente ligado a divisão do trabalho realizada por essas modernas "fábricas de notícias", tornado 
obsoleto os chamados redatores de banca, que escreviam sobre todos os assuntos, criando-se a partir daí “...divisões na redação, com variados setores de reportagens, chefiados por um secretário, auxiliado por paginadores, elementos de ligação das oficinas com as redações" (BARBOSA, 1996: 22).

Interessante notar que a consagração do repórter, e a sua saída do anonimato, ocorre na proporção direta do seu sucesso como escritor ou cronista, fato incomum para a grande maioria dos empregados nessa função. Talvez por esse motivo, Euclides da Cunha seja citado como o primeiro repórter brasileiro, em face da sua cobertura da Guerra dos Canudos, como correspondente pelo O Estado de S. Paulo, em 1896, cujo conjunto de reportagens resultou na publicação de Os Sertões. O cronista João Paulo Barreto, o João do Rio, também representa um caso inédito de repórter com grande consagração popular (GOMES, 1996). Porém, a grande maioria dos repórteres do período não alcançaram tamanho prestígio, e caíram no esquecimento ${ }^{1}$.

A velocidade na apuração das notícias exigia um grande esforço para o repórter nesses primórdios, pois na maioria das vezes, a rapidez dos acontecimentos não era acompanhada pela tecnologia e eficiência dos transportes disponíveis, numa cidade que acabara de descobrir a eletricidade como nova força para encurtar distâncias (MENDONÇA, 2001). Para a apuração das notícias, era fundamental a presença física dos repórteres, sobretudo os de polícia, que precisavam cruzar a cidade, quase sempre de trem e, na falta do transporte, muitas vezes a pé, o que tornava "deveras penoso o trabalho de reportagem" (NETTO, 1998: 51-52) nessa corrida contra o tempo. Como destaca Marialva Barbosa: "O jornal tinha hora para sair das oficinas para as ruas e, nesse contexto, o tempo tornava fator preponderante. $\mathrm{O}$ tempo da apuração das notas, $o$ tempo da redação das notícias, o tempo da sua distribuição, tudo era regulado pela premência de uma nova realidade temporal que também tomava conta da cidade" (BARBOSA, 1996: 60).

Nesse corre-corre frenético entre as redações e as ruas, o repórter distancia-se do flaneur de Charles Baudelaire, na medida em que o flaneur, andando a esmo, passeia na cidade em busca dos lugares onde o passado ainda apresenta seus vestígios, ao passo

\footnotetext{
${ }^{1}$ Em 1904, o Almanaque Laemmert publica a relação de vinte e oito repórteres em atividade nos periódicos da época, entre os quais Ernesto Senna, do Jornal do Commercio, Castela de Carvalho, de A Notícia, Gustavo de Lacerda, de O Paiz, Baldomero Carqueja, do Jornal do Commercio, Eugênio Pereira, da Gazeta de Notícias, entre outros. In: Almanaque Laemmert, Rio de Janeiro, Tip. Universal, 1904. Apud BARBOSA, Marialva (1996). Imprensa, Poder e Público (Os diários do Rio de Janeiro - 18801920). Universidade Federal Fluminense. Pós-Graduação em História/Instituto de Ciências Humanas e Filosofia. Imprensa, Poder e Público. Os diários do Rio de Janeiro, 1880-1920. Niterói, Tese (Doutorado): 79.
} 
que para o repórter só existe o hoje, “...o ontem representa um passado distante e o amanhã um futuro longínquo. O que importa é a notícia que tem que ficar pronta na próxima edição, e o tempo não espera ou abre exceção" (TRAVANCAS, 1993: 35). A urgência dos leitores por novas informações, impele cada vez mais os repórteres para as ruas, tornando-as o lócus privilegiado da sua função, espaço onde tudo acontece, e o repórter “...constrói sobre o momento, a história dos fatos presentes” (MEDINA, 1988: 58).

Para Marialva Barbosa, esse foi um momento verdadeiramente revolucionário para a imprensa da época, caracterizado pela transformação dos pequenos jornais de estrutura simples, em empresas jornalísticas de estruturas complexas, detentoras de um grande poder econômico e capital simbólico que, para além de aparentes divergências entre si, e com linhas editoriais distintas, "estavam coesos na difusão da mesma ideologia - a do progresso - fomentando ao mesmo tempo, a disciplinarização" (BARBOSA, 1996: 28).

\section{Imprensa e modernidade carioca dos anos de 1950}

Assim como a imprensa de começo do século XX em relação à implantação da República, a imprensa brasileira dos anos de 1950 também desempenhou função estratégica na transição do Brasil para um país moderno, promovendo a padronização dos valores de uma nova sociedade urbano-industrial em ascensão.

A modernidade dos anos de 1950 produziu um novo tipo de sociabilidade, associada ao aceleramento da urbanização e dos meios de comunicação de massa, ao crescimento econômico e a diferenciação de padrões de comportamento. Fenômenos que produziram uma diferenciação maior dos tipos urbanos, estimulada ainda pelo intenso fluxo migratório de outros estados, e pelo estabelecimento de novas territorialidades culturais na cidade do Rio de Janeiro, às vésperas da transferência do distrito federal para Brasília.

A modernidade carioca dos 50 foi especialmente favorável para as classes médias urbanas que viveram o boom de desenvolvimento industrial e de otimismo pósguerra iniciado no segundo governo Vargas, entre 1951 e 1954, e acelerado no governo Juscelino Kubitschek, entre 1956 a 1960. Esse processo correspondeu também ao 
surgimento de novos segmentos intelectuais contagiados pelo espírito do novo e a vontade de mudança, promovendo o nascimento de importantes movimentos no campo artístico com novas formas de conceber o cinema, o teatro, a música, a poesia e as artes plásticas.

Novos jornais e revistas foram criados, outros fizeram modificações na forma de apresentar e diagramar suas matérias, e a tradicional imprensa brasileira de forte influência francesa, foi abandonando uma de suas mais antigas tradições: o jornalismo de combate, de crítica, de doutrina e de opinião, voltando-se cada vez para o modelo de jornalismo norte-americano, "que privilegia a informação e a notícia e que separa o comentário pessoal da transmissão objetiva e impessoal da informação" (ABREU, 1996: 18).

Na conjuntura do pós-guerra, caracterizada pela ascensão da mulher no mercado de trabalho e na sociedade de consumo, as faculdades de jornalismo também contribuíram para o ingresso das mulheres nas redações dos jornais, fato inédito até os anos 50. Inicialmente limitadas ao chamado jornalismo feminino, pouco a pouco as jornalistas, mesmo que ainda em minoria, foram tratando dos assuntos tradicionalmente reservados aos homens, chegando às duas últimas décadas do século $\mathrm{XX}$, a se constituírem em maioria dessa categoria profissional. A par dos novos cursos de jornalismo, a grande escola continuava a ser as redações dos jornais, cujo passaporte infalível para o seu ingresso era, além do talento para a escrita, pertencer à restrita rede de sociabilidade dos intelectuais que dominavam o setor, e de onde surgiriam as primeiras oportunidades para tomar parte desse círculo fechado da imprensa carioca.

A recuperação desse passado revolucionário da imprensa carioca passa, necessariamente, pelas histórias de vida dos jornalistas, diretores e donos dos jornais, considerando o peso da iniciativa individual nessa fase de pioneirismo, onde quase tudo ainda estava por construir. Referir-se a Última Hora, era falar do jornal de Samuel Wainer, assim como da Tribuna da Imprensa, de Carlos Lacerda; O Globo, de Roberto Marinho, Correio da Manhã, de Paulo Bittencourt; Diário de Notícias, de Orlando Dantas; Diário Carioca, de Horácio de Carvalho, entre outros "barões da imprensa", como assim os denominou Samuel Wainer (WAINER, 1987: 224).

Além da circulação dos aproximadamente 22 vespertinos e matutinos, polarizados entre sindicatos, Igreja, partidos de esquerda e, principalmente, entre as teses nacionalistas, foi também o tempo das grandes revistas, com O Cruzeiro, dos Diários Associados de Assis Chateaubriand atingindo 570 mil exemplares semanais, 
marca máxima até então registrada no país, seguida pela rival Manchete fundada em 1952 por Adolfo Bloch, cuja edição especial da inauguração de Brasília chegou a esgotar os seus 740 mil exemplares em apenas 48 horas. A revista feminina Cigarra, também dos Associados, Manchete Esportiva e a popular revista de variedades $O$ Mundo Ilustrado, lançada em 1956 pelo Mundo Gráfico e Editora, superavam as expectativas, isso para falar apenas das mais conhecidas (MESQUITA, 2008: 145).

Essa "época de ouro" da imprensa brasileira, contava com vultosos empréstimos do governo, em um período anterior à entrada do capital publicitário, mas sobrevivia, fundamentalmente, dos grandes nomes do jornalismo, no momento em que o colunismo moderno despontava como mais uma novidade introduzida pelo jornal Última Hora ${ }^{2}$, caracterizada pela parcialidade da opinião do autor nas seções diárias sobre futebol, política, polícia, sociedade, divertimento. Fazia-se um jornalismo de jornalistas, em que o leitor não ia atrás apenas da imparcialidade da notícia, mas principalmente, da opinião dos seus colunistas favoritos. Assim, o prestígio popular de determinados jornais e a independência criativa dos colunistas, fez surgir, da noite para o dia, verdadeiras celebridades, como Adalgisa Nery, Paulo Francis, Nelson Rodrigues, Antonio Maria, e Stanislaw Ponte Preta, donas de um público cativo que as acompanhavam em qualquer jornal. Ainda como representantes dessa geração pródiga em talento, as opiniões sobre política de Villas-Boas Corrêa a Castello Branco, passando por Otto Maria Carpeaux, Newton Carlos, Hélio Fernandes e Danton Jobim, eram assunto nas rodas inteligentes, assim como os comentários esportivos de José Araújo, João Saldanha, Sandro Moreyra e Armando Nogueira provocavam discussões polêmicas e apaixonadas. A classe média passou a acompanhar a vida do "café-society", graças ao colunismo social de Jachinto de Thormes, Fernando Zerlottini — o Carlos Swan, e Ibrahim Sued.

José Cândido de Carvalho era outro que pontificava na imprensa da época, ao lado dos expoentes da crônica que se impunha como um gênero essencialmente jornalístico, popularizando, nos recém lançados suplementos culturais e literários, nomes como Rubem Braga, Manoel Bandeira, Fernando Sabino, Paulo Mendes Campos, e o poeta Carlos Drummond de Andrade. O humor era imbatível, com Péricles e seu “Amigo da Onça”, Stanislaw e suas “certinhas”, Vão Gôgo — pseudônimo de

\footnotetext{
${ }^{2} \mathrm{Na}$ verdade, o Última Hora foi responsável pela re-introdução do colunismo nos anos 50 que, muito intenso desde o florescimento da imprensa brasileira no século XIX, entra em decadência ao final dos anos 20 em função da "crise econômica de 29, dos movimentos revolucionários de 1930, 32 e 35 e dos anos da ditadura Vargas". BARROS, Theodoro de (1993). Imprensa era dominada por um grupo familiar até 1950. In: CAMPOS, Anderson (org). A Última Hora de Samuel: nos tempos de Wainer. Rio de Janeiro: ABI/Copim: 16.
} 
Millôr Fernandes e sua coluna "Pif-Paf, "As Garotas" do desenhista de modas Alceu Pena, com piadas de A. Ladino, e Leon Eliachar com suas sátiras sobre a rivalidade entre os sexos. Enquanto nas redações, Pompeu de Souza, Jânio de Freitas, Alberto Dines revolucionavam a maneira de fazer o jornalismo brasileiro, as grandes reportagens, como as de Joel Silveira e da dupla David Nasser e o fotógrafo Jean Manzon mexiam com a opinião pública. O principal crítico de cinema era Salvyano Cavalcanti, e os caricaturistas Borjalo, Millôr, Jaguar, Carlos Estevão, Augusto Rodrigues, Nássara, Lan e Hilde completavam com seu traço irreverente o painel crítico e extremamente criativo dessa nova realidade. De acordo com Beatriz Resende:

O ano de 1956 marca o início da era dos suplementos culturais e literários. É lançado o Suplemento Dominical do Jornal do Brasil. Carlos Drumond de Andrade escreve no Correio da Manhã os textos que serão reunidos em Fala, amendoeira. Em 1957, Manoel Bandeira usa suas crônicas jornalísticas para defender os rapazes concretistas 'impressionantemente sérios, a ponto de acreditarem que sua concepção de arte poderá classificar a consciência brasileira, melhorar a condição social do Brasil (RESENDE, 1995: 12).

$\mathrm{Na}$ segunda metade dos anos 50, a crescente radicalização política atingia a todos os jornais cariocas envolvidos nesse momento de renovação da imprensa brasileira, Última Hora foi um dos mais representativos. Segundo Carlos Castello Branco, o jornal fundado por Samuel Wainer em 1951, foi criado para ser "a Volta Redonda da imprensa brasileira",3, comparando a siderúrgica que alavancou o projeto getulista de modernização do país, com o jornal criado para atender aos anseios populares e nacionalistas do segundo governo Vargas, então isolado pela grande imprensa. Assim, o Última Hora tornou-se pioneiro de uma imprensa popular de grande circulação (LAURENZA, 1999), responsável pelo rompimento da tradição oligárquica que controlava a opinião pública com meia dúzia de jornais pertencentes a famílias tradicionais (WAINER, 1987: 133).

Inicialmente utilizada como efeito visual, o radicalismo político da época produziu momentos antológicos da charge política brasileira, como a criação de $O$ Corvo, figura associada a Carlos Lacerda, proprietário da Tribuna da Imprensa, jornal antigetulista e arquinimigo de Samuel Wainer. Graças ao talento dos traços de Lan e a penetração popular do $U H$, Lacerda jamais conseguiu se desvencilhar desse apelido

\footnotetext{
${ }^{3}$ BRANCO, Carlos Castelo. Apud FERREIRA, Marieta de Moraes; MESQUITA, Cláudia. Os anos JK na Biblioteca Nacional, op. cit.: 114.
} 
sinistro, bem como suas eleitoras da pecha de malamadas, cunhada pelo cronista Antonio Maria que, segundo o próprio Lacerda, define pejorativamente "criaturas que não eram suficiente amadas pelos respectivos maridos ou namorados e que se fixavam em mim, como um mito, assim, machista... Era como se você dissesse 'as solteironas"' (LACERDA, 1978: 223).

No clima da efervescência cultural dos anos de 1950, as redações cariocas eram muito barulhentas e enfumaçadas, com um corre-corre frenético de repórteres, contínuos, secretárias, diagramadores, cujo barulho se misturava com o "tec-tec-tec" nervoso das máquinas voltadas para o fechamento dos matutinos e vespertinos, que chegavam às bancas da cidade ou eram distribuídos pela entrega ambulante. Um veterano repórter, assim descreve sua primeira impressão da redação da "velha" Tribuna da Imprensa, na Rua do Lavradio 98, onde:

[...] de longe podíamos ouvir o barulho das máquinas de escrever, atrás das quais estavam mulheres e rapazes em manga de camisas, uns batendo no teclado, outros falando ao telefone, sem contar com os que liam jornais. Tudo dentro de um rítmico dinâmico... Fazia muito calor...Um ventilador rodava sem parar e pairava no ar uma grossa nuvem de fumaça de cigarro (BACIU, 1982: 43).

Porém, se por um lado a imprensa carioca foi a principal responsável pela invenção do Rio como uma cidade ideal, por outro coube também aos seus repórteres, desvelar contradições e mazelas da febre modernizadora do governo JK, revelando uma cidade real, carente de melhoramentos urbanos e serviços públicos essenciais. Os jornais diários publicavam reportagens sobre a precariedade da limpeza pública de alguns bairros cariocas, ainda puxada a burros, o abastecimento de água que não chegava para a maioria da população, o sofrimento dos pais de alunos um horas e horas em filas para conseguir vagas em escolas, e os famosos "apagões", realidade diária que o humor carioca traduziu na famosa paródia carnavalesca: "cidade maravilhosa, cheia de encantos mil, de dia falta água, de noite falta luz".

Os cariocas na condição de "hospedeiros" do poder central, teriam adquirido uma natureza crítica e um humor irreverente como forma de subversão à ordem opressora da cidade-capital. O riso como tática de subversão ao medo e à intimidação dirigidos às classes populares, deu origem à cultura cômica popular onde, "por meio de 
canções... inversões e utilizações jocosas de signos do poder, os populares demonstraram sua resistência a situações que lhes eram opressivas" (SOIHET, 1998: 14).

Ainda na segunda metade dos anos de 1950, as manchetes estampavam enchentes que castigavam os cariocas no verão, causavam desabamentos e mortes, e as "ressacas" da orla continuavam a fazer os mesmos estragos de princípios do século XX, derrubando muretas e comendo asfalto. A crise de abastecimento era constante: faltava peixe na Páscoa, a carne era escassa o ano inteiro, tornando seu preço exorbitante e proibitivo à maioria da população. As evidências desse atraso no dia a dia dos cariocas, convivendo lado a lado com uma vida cultural efervescente, uma natureza exuberante, e os traços arquitetônicos de cidade capital, faziam do Rio uma cidade "sui generis", um espaço de contrastes.

A nova febre modernizadora que tomou o Rio nos anos 1950 provocou um rápido e caótico crescimento urbano, com demolições de antigos casarões, teatros, cinemas, bares, aberturas de ruas e avenidas, cuja "febre viária" trouxe de volta a "antiga prática da cirurgia urbana" de Pereira Passos, cujos efeitos na segunda metade do século XX se fizeram sentir "principalmente nos bairros que estavam no caminho das novas vias expressas, túneis e viadutos” (ABREU, 1997: 95). Essas intervenções urbanas ocorridas na chamada "época de ouro" da cidade do Rio de Janeiro, provocaram um sentimento de deslocamento, perda de identidade e processo de exclusão social. Do ponto de vista político, os últimos anos do governo Kubitschek corresponderam ao esgotamento do modelo nacional-desenvolvimentista, com Juscelino declarando rompimento do Brasil com o Fundo Monetário Internacional e, mais uma vez, tentando manter o equilíbrio democrático, sufocando com habilidade política a revolta de Aragarças, no território de Goiás.

Esse contexto de modernidade em uma "capital provisória", como assim a definiu o jornalista Sérgio Porto (MESQUITA, 2008), fez da segunda metade dos anos de 1950 um momento sui generis e uma época profícua para a recriação da identidade local, onde os intelectuais cariocas estiveram particularmente envolvidos nesse processo de "transbordamento da memória" para usar a expressão de Jacques Le Goff sobre os momentos de expansão das memórias coletivas (LE GOFF, 1994: 426). A perspectiva da criação de Brasília foi um dos fatores propulsores da febre de "carioquismo" que tomou a imprensa carioca a partir da metade dos anos de 1950, em função do sentimento de incerteza quanto ao seu futuro de ex-capital federal. Jornalistas das mais 
variadas matizes partidárias e ideológicas, diante da inexorável mudança da capital, tiveram um papel fundamental na mobilização da população local frente a uma suposta ameaça de esvaziamento do Rio de Janeiro (MESQUITA, 2009).

Com a transferência da capital, a autonomia política da cidade-capital, consolidada com a criação da Guanabara em 14 de abril de 1960, correspondeu à necessidade do estabelecimento de um novo território com uma nova identidade política e cultural, mobilizando para isso mediadores, marcos fundadores e mitos de origem associados na formação dessa "comunidade imaginada", para usar o já clássico conceito de Benedict Anderson (ANDERSON, 1989). A imprensa exerceu um papel fundamental nesse empreendimento, constituindo-se em um celeiro de ideias e estratégias na constituição simbólica da cidade do Rio de Janeiro, ajudando fixar elementos com que o Rio viria a ser identificado dentro e fora do país.

O negócio é mesmo chamar o Distrito Federal de Estado da Guanabara, que não é um mau nome, e dar-lhe como capital o Rio de Janeiro, continuando os seus filhos a se chamarem cariocas. Imaginem só chegarem para a pessoa e perguntarem de onde ela é, o ela ter de dizer: "Sou guanabarino, ou guanabarense". Não é de morte? Um carioca que se preza nunca vai abdicar de sua cidadania. Ninguém é carioca em vão. Um carioca é um carioca. Ele não pode ser nem um pernambucano, nem um mineiro, nem um paulista, nem um baiano, nem um amazonense, nem um gaúcho. Enquanto que, inversamente, qualquer uma dessas cidadanias, sem diminuição de capacidade, pode transformar-se também em carioca; pois a verdade é que ser carioca é antes de mais nada um estado de espírito (MORAES, 1981: 5).

A partir da valorização do passado e das tradições locais, apostava-se no alívio do Rio deixar de abrigar uma incômoda e crescente burocracia do governo central, e no modelo da mais cosmopolita cidade americana que, embora sem o estatuto políticojurídico de capital federal, era de fato a capital financeira, comercial e cultural dos Estados Unidos. Para os bairristas cariocas bastava esse tipo de compensação, pois para a maioria que diariamente se manifestava na imprensa sobre o assunto, era consenso que todos sairiam ganhando com a transferência da capital.

Assim, para além do conjunto de transformações estéticas e empresariais e do seu grande envolvimento com a política nacional, a imprensa carioca foi um dos principais mediadores da afirmação do Rio metrópole no momento em que buscava seu destino como ex-capital do país. Repórteres, cronistas e colunistas, profissionais paradigmáticos da moderna imprensa dos anos de 1950, para além dos aparatos formais 
da profissão, constituíram uma comunidade interpretativa (ZELIZER, 2000) pois agindo enquanto comunidade, foram especialmente pródigos na criação de um novo perfil de cidade e de um "jeito de ser carioca".

\section{Referências bibliográficas}

ALMEIDA, Lara Monique Oliveira. "Eugênia Brandão: a primeira repórter do Brasil". Disponível em: http://www.ufrgs.br/alcar/encontros-nacionais-1/encontrosnacionais/6o-encontro-2008-1/EUGENIA\%20BRANDaO.pdf. Acesso em: $11 \mathrm{de}$ outubro de 2020.

ABREU, Alzira Alves de (org.) (2002). A modernização da imprensa (1720-2000). Rio de Janeiro: Jorge Zahar.

ABREU, Maurício de Almeida (1987). Evolução urbana do Rio de Janeiro. Rio de Janeiro: IPLAN/RIO-Jorge Zahar.

ANDERSON, Benedict (1989). Nação e consciência nacional. Rio de Janeiro: Ática.

BACIU, Stefan (1982). Lavradio 98: histórias de um jornal de oposição: A Tribuna da Imprensa ao tempo de Carlos Lacerda. Rio de Janeiro: Nova Fronteira.

BAHIA, J. (1990). Jornal, história e técnica: história da imprensa brasileira. São Paulo: Ática.

BARBOSA, Marialva (1996). Imprensa, Poder e Público (Os diários do Rio de Janeiro - 1880-1920). Universidade Federal Fluminense. Pós Graduação em História/Instituto de Ciências Humanas e Filosofia. Imprensa, Poder e Público. Os diários do Rio de Janeiro, 1880-1920. Niterói. Tese (Doutorado).

BOURDIEU, Pierre (1989). O poder simbólico. Rio de Janeiro: Bertrand Brasil.

CADERNOS DA COMUNICAÇÃO (2002). Mulheres em revista: o jornalismo feminino no Brasil. Rio de Janeiro: Secretaria Especial de Comunicação Social.

CAMPOS, Anderson (org) (1993). A Última Hora de Samuel: nos tempos de Wainer. Rio de Janeiro: ABI/Copim.

CANDIDO, Antonio et alli (1992). A crônica, sua fixação e suas transformações no Brasil. Campinas: UNICAMP; Rio de Janeiro: Fundação Casa de Rui Barbosa.

DIAS, Ângela Maria (1995). Memória da cidade disponível: foi um Rio que passou em nossas vidas. A crônica dos anos 60. In: RESENDE, Beatriz (Org.). Cronistas do Rio. Rio de Janeiro: J. Olympio: CCBB.

FERREIRA, Marieta de; MESQUITA, Cláudia (2001). Os anos JK na Biblioteca Nacional. In: PEREIRA, Paulo Roberto. Brasiliana da Biblioteca Nacional: guia Rio de Janeiro: Nova Fronteira.

GADINI, Sérgio Luíz (2003). A cultura como notícia no jornalismo brasileiro. Rio de Janeiro: Prefeitura da Cidade do Rio de Janeiro: Secretaria Especial de Comunicação Social. Cadernos de Comunicação. Série Estudos, v. 8.

GOMES, Ângela de Castro (1999). Essa gente do Rio: modernismo e nacionalismo. Rio de Janeiro: FGV.

GOMES, Renato Cordeiro (1996). João do Rio: Vielas do vício, ruas da graça. Relume Dumará/ Prefeitura da Cidade do Rio de Janeiro. Perfis do Rio n. 13.

HERMANO, Viana (1995). O mistério do samba. Rio de Janeiro: Zahar/UFRJ.

HOBSBAWM, Eric; RANGER, Terence (org.) (1984). A invenção das tradições. Rio de Janeiro: Paz e Terra.

JOBIM, Danton (1992). Espírito do jornalismo. São Paulo: Edusp, Com-Arte. 
LACERDA, Carlos (1978). Depoimento. Rio de Janeiro: Nova Fronteira.

LAURENZA, Ana Maria de Abreu (1999). Lacerda X Wainer: o corvo e o bessarabiano. Rio de Janeiro: Senac.

MENDONÇA, Leila Lobo (coord) (2001). Cidade em Movimento: energia elétrica e meios de transporte no Rio de Janeiro. Centro da Memória da Eletricidade no Brasil. Rio de Janeiro: Memória da Eletricidade.

MESQUITA, Cláudia (2008). De Copacabana à Boca do Mato: O Rio de Janeiro de Sérgio Porto e Stanislaw Ponte Preta. Rio de Janeiro: Editora Casa de Rui Barbosa

MESQUITA, Cláudia (2016). "De Cidade Maravilhosa à Cidade Mulher: o Rio de Janeiro de Alvaro Moreyra e seus discípulos”. In: OLIVEIRA, Cláudia, Cláudia Mesquita e Joelle Rouchou. (org.). A Cidade Mulher. Alvaro Moreyra. Rio de Janeiro: Mauad Editora/FAPERJ.

MESQUITA, Cláudia (2009). Um Museu para a Guanabara: Carlos Lacerda e a criação do Museu da Imagem e do Som (1960-1965). Rio de Janeiro, Folha Seca/FAPERJ.

MORAES, Vinícius (1981). Estado da Guanabara. Para Viver um Grande Amor. Rio de Janeiro: J. Olympio.

NETTO, Accioly (1998). O Império de Papel: os bastidores de O Cruzeiro. Porto Alegre: Sulina.

RESENDE, Beatriz (org.) (1995). Cronistas do Rio. Rio de Janeiro, José Oympio.

RIBEIRO, Ana Paula (2003). Jornalismo, literatura e política: a modernização da imprensa carioca nos anos 50. Estudos Históricos. Rio de Janeiro, número 31.

SILVA, Adriana Hassin (2003). A modernidade em alvorada: Brasília e a imagem do Brasil moderno no fotojornalismo d'O Cruzeiro e da Manchete (1956-1960). Dissertação (Mestrado)-PGHIS/IFCS/UFRJ, Rio de Janeiro.

SILVEIRA, Joel (1993). Tempo de Contar. Rio de Janeiro: José Olympio.

SOIHET, Rachel (1998). A subversão pelo riso: estudos sobre o carnaval carioca da belle époque ao tempo de Vargas. Rio de Janeiro: FGV.

TRAQUINA, Nelson (org) (2000). Revista de comunicação e linguagens: jornalismo 2000. Lisboa: Relógio D'Água.

TRAVANCAS, Isabel (1993). O mundo dos jornalistas. São Paulo: Summus.

VELHO, Gilberto; KUSCHNIR, Karina (orgs) (2000). Mediação, cultura e política. Rio de Janeiro: Aeroplano.

VELLOSO, Mônica Pimenta (1996). Modernismo no Rio de Janeiro: turunas e quixotes. Rio de Janeiro: FGV.

VIANNA, Hermano (1995). O mistério do samba. Rio de Janeiro: Zahar/UFRJ.

WAINER, Samuel (1987). Minha razão de viver: memórias de um repórter. Rio de Janeiro: Record.

ZELIZER, Barbie (2000). Os jornalistas enquanto comunidade interpretativa. In: TRAQUINA, Nelson (org). Revista de comunicação e linguagens: jornalismo. Lisboa: Relógio D'Água.

Artigo recebido em 18 de novembro de 2020.

Aprovado em 01 de dezembro de 2020.

DOI: $10.12957 /$ intellectus.2020.56115 